\title{
Timo intratiroideo, una causa infrecuente de nódulo tiroideo en niños
}

\author{
FABIOLA VARGAS P. ${ }^{1}$, KARLA MOËNNE B. $^{2}$, XIMENA ORTEGA F. $^{2}$ \\ 1. Becada Radiología Infantil, Clínica Las Condes-Universidad de Chile. \\ 2. Radióloga Infantil, Departamento de Diagnóstico por Imágenes, Clínica Las Condes
}

\begin{abstract}
Intrathyroidal thymic tissue, a rare cause of thyroid nodules in children

Thyroid nodules (TN) are uncommon in children. Despite TN have a higher risk of malignancy in children than in adults, in most cases, this is a rare finding and benign most of the time. The presence of intrathyroid thymic tissue may mimic the existence of a pathological node. The case of an 11-year-old female patient with a thyroid nodule incidentally detected during cervical ultrasonography and corresponding to intrathyroidal thymic tissue is presented. The goal of this research is to further study this condition to avoid unnecessary invasive diagnostic procedures.
\end{abstract}

(Key words: Intrathyroidal thymic tissue, nodule, thyroid, children).

Rev Chil Pediatr 2014; 85 (1): 94-97

\section{RESUMEN}

Los nódulos tiroideos (NT) son muy infrecuentes en niños. Si bien los NT tienen mayor riesgo de malignidad en niños que en adultos, en la mayoría de los casos se trata de un hallazgo casual, cuya etiología es mayoritariamente benigna. La presencia de tejido tímico normal intratiroideo puede simular la existencia de un nódulo patológico. Se presenta el caso de una escolar de 11 años en la que se pesquisa incidentalmente un nódulo tiroideo en ultrasonografía cervical, correspondiente a un foco de timo intratiroideo. Nuestro objetivo es actualizar el conocimiento de esta entidad para evitar procedimientos diagnósticos invasivos innecesarios.

(Palabras clave: Timo intratiroideo, nódulo, tiroides, niños).

Rev Chil Pediatr 2014; 85 (1): 94-97

Recibido el 9 de septiembre de 2013, devuelto para corregir el 25 de noviembre de 2013, segunda versión 30 de diciembre de 2013, aceptado para publicación el 6 de enero de 2014.

Este trabajo cumple con los requisitos sobre consentimiento /asentimiento informado, comité de ética, financiamiento, estudios animales y sobre la ausencia de conflictos de intereses según corresponda.

Correspondencia a:

Dra. Fabiola Vargas P.

E-mail: fabivarpe@hotmail.com 


\section{Caso clínico}

Escolar de 11 años, de sexo femenino, en control y tratamiento por pubertad precoz e hirsutismo. Se le solicitó US de tiroides que pesquisó un nódulo en el aspecto posterior del tercio medio del lóbulo tiroideo derecho, descrito como: bien delimitado, de morfología redondeada y dimensiones aproximadas de 9 × 4 × $6 \mathrm{~mm}$, hipoecogénico con ecos
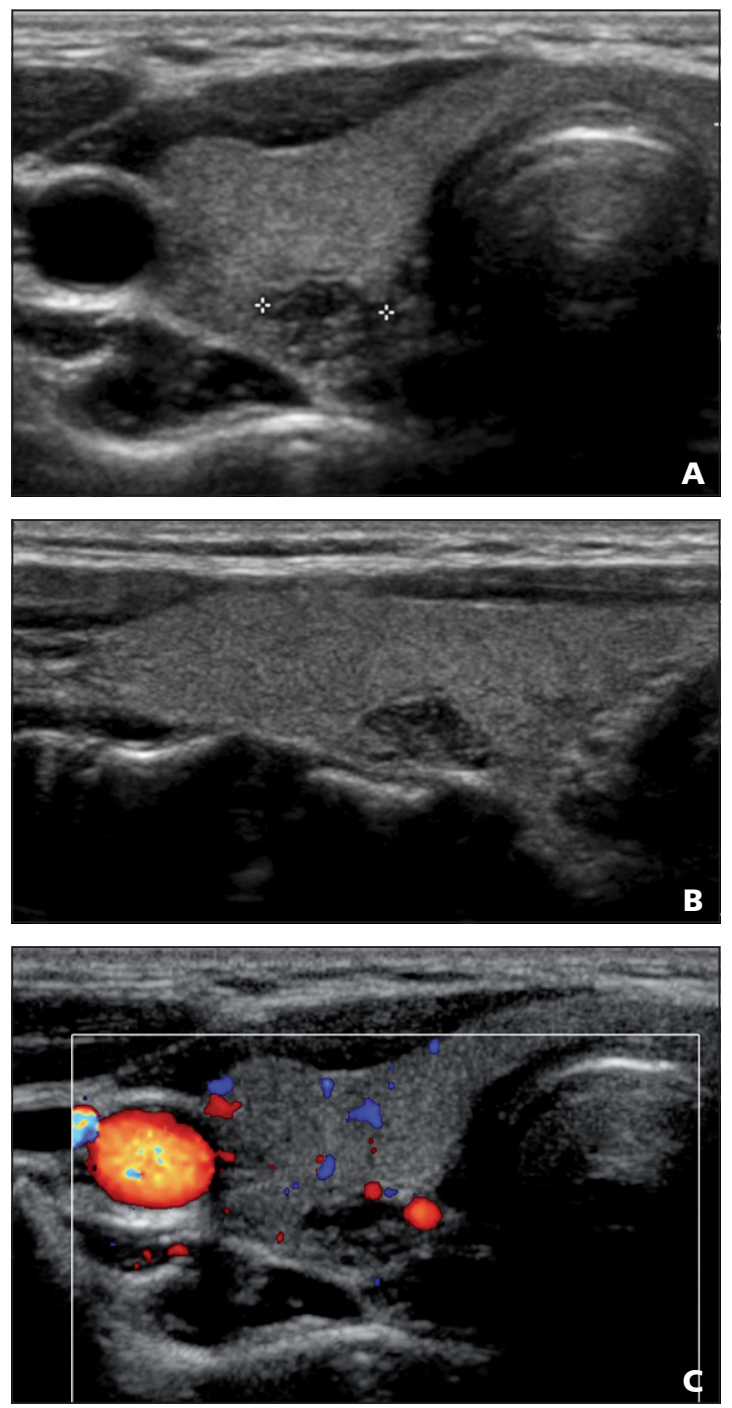

Figura 1. US demuestra nódulo hipoecogénico en el tercio medio del lóbulo tiroideo derecho, con septos ecogénicos y escasa vascularización en su espesor: Corte transversal (A), longitudinal (B) y Doppler color (C). lineales y puntiformes de mayor ecogenicidad en su espesor y menor vascularización que el tejido tiroideo adyacente al ser investigado con Doppler color (figura 1). Se realizó control ecográfico seis meses después, demostrándose persistencia del nódulo sin variaciones significativas respecto a examen previo (figura 2) y presencia de tejido tímico normal en base del cuello, región supraesternal (figura 3).
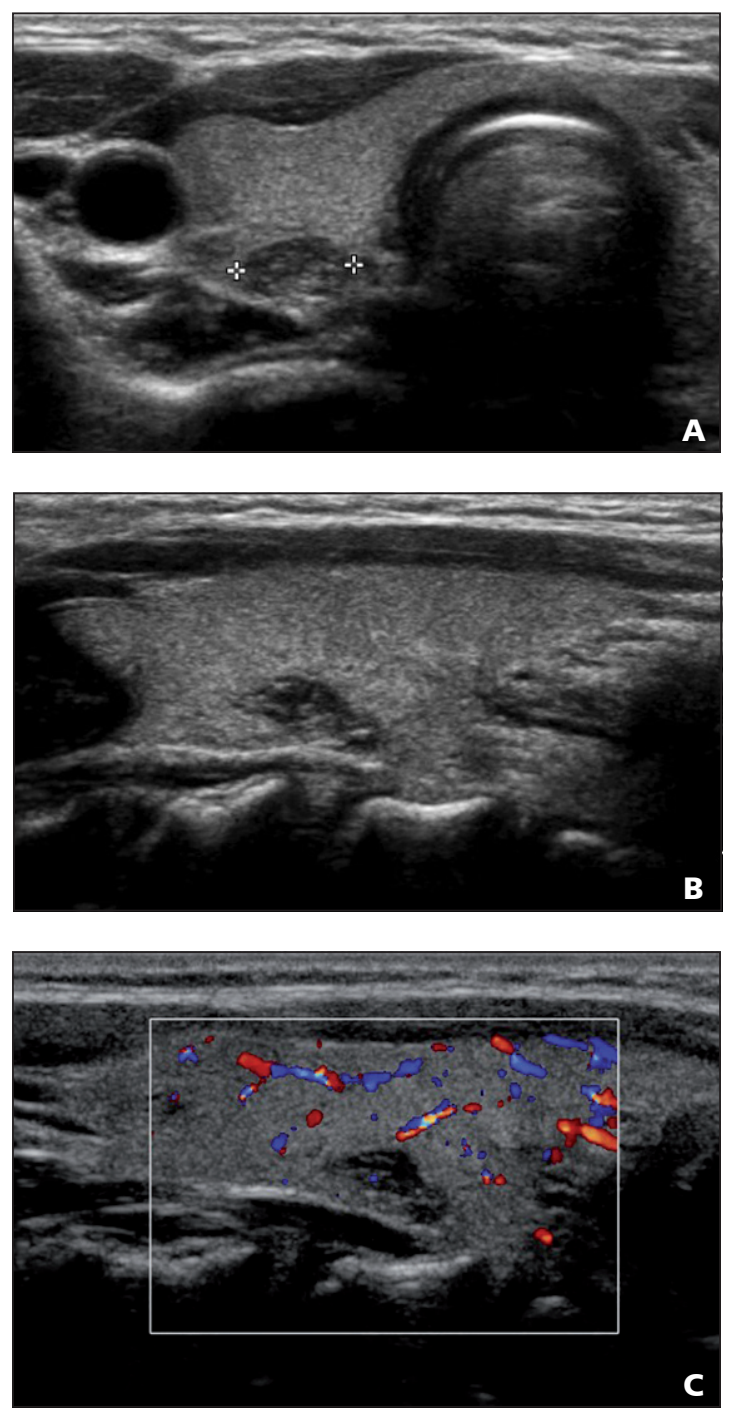

Figura 2. US de tiroides efectuada 6 meses más tarde muestra nódulo sin cambios: Corte transversal (A), longitudinal (B) y Doppler color (C). 

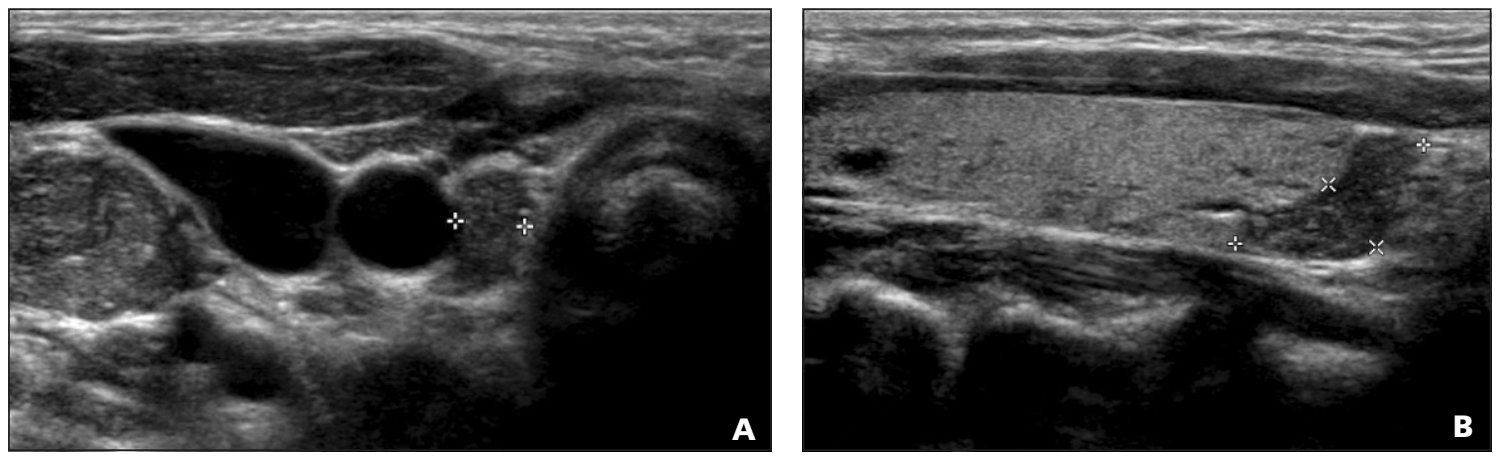

Figura 3. US cervical de la misma paciente demuestra presencia de tejido tímico en la región supraesternal derecha, adyacente al aspecto caudal del lóbulo tiroideo derecho, con características ecográficas idénticas al nódulo descrito en el lóbulo tiroideo derecho: Corte transversal (A) y longitudinal (B).

\section{¿Cuál es su diagnóstico?}

\section{Diagnóstico}

Timo intratiroideo.

\section{Discusión}

En niños, la gran mayoría de las lesiones nodulares de la glándula tiroides es de origen coloideo; con menos frecuencia se encuentran carcinomas y adenomas ${ }^{1}$. Si bien la incidencia de nódulos tiroideos es menor en la edad pediátrica en relación a los adultos, ante un nódulo sólido solitario el riesgo de malignidad es mayor en niños que en adultos ${ }^{1,2}$, siendo los carcinomas tiroideos el $1,4 \%$ de los tumores malignos en la edad pediátrica ${ }^{1,3}$.

El timo es el órgano central del sistema linfoide en la infancia y juega un rol importante en la inmunidad celular, mediante la generación de linfocitos $\mathrm{T}$ circulantes. Anatómicamente se trata de una estructura bilobulada, que contiene elementos derivados de las tres capas germinales, originada en tercer y cuarto par de bolsas branquiales alrededor de la quinta o sexta semana de gestación. El timo intratiroideo es una entidad poco frecuente, que corresponde a una condición benigna originada en migración aberrante del timo durante la embriogénesis ${ }^{4}$; el tejido tímico se puede localizar a lo largo de la ruta de descenso habitual en el período embrionario, desde el cuello hasta el mediastino anterior ${ }^{5}$. Los descensos del timo y de la glándula tiroides están íntimamente relacionados, debido a la proximidad del divertículo tiroideo con las bolsas branquiales de las que deriva el timo durante la vida intrauterina ${ }^{6}$.

El timo ectópico intratiroideo es una causa rara de nódulo tiroideo, que habitualmente se descubre de forma incidental ${ }^{3}$ en exámenes solicitados por otras causas ${ }^{6}$, pudiendo diagnosticarse erróneamente como nódulos o masas patológicas, que potencialmente conduzcan biopsias o tratamientos quirúrgicos innecesa$\operatorname{rios}^{6,7}$. Los pacientes se presentan asintomáticos y sin hallazgos patológicos al examen físico; en los casos reportados no se describe asociación a bocio ni nódulos palpables ${ }^{7}$.

En los pocos casos pediátricos reportados en la literatura existen pacientes de ambos sexos en similar proporción, sin claro predominio de ninguno de ellos ${ }^{7}$. La causa precisa de esta entidad es desconocida y no se describen posibles factores de riesgo ni presencia de patologías asociadas.

La detección de este tejido ectópico ha aumentado con el uso cada vez más frecuente de la ultrasonografía (US). La verdadera incidencia de la inclusión de timo dentro de la tiroides es desconocida, dado que la gran mayoría presenta un curso asintomático. Es importante destacar que el patrón ultrasonográfico carac- 
Tabla 1. Características ultrasonográficas de los nódulos tiroideos

\begin{tabular}{|lllll|}
\hline Tipo & Características & $\begin{array}{c}\text { Ultrasonido } \\
\text { Contornos/ Localización }\end{array}$ & Flujo & $\begin{array}{c}\text { Linfonodos } \\
\text { sospechosos }\end{array}$ \\
Timo intratiroideo & $\begin{array}{l}\text { Sólido hipoecogénico, finos } \\
\text { septos o puntos ecogénicos }\end{array}$ & Definidos & Escaso o (-) & $(-)$ \\
Nódulo maligno & $\begin{array}{l}\text { Sólido hipoecogénico, con } \\
\text { microcalcificaciones }\end{array}$ & Irregulares + Subcapsulares & $\begin{array}{l}\text { Flujo central o vaso } \\
\text { penetrante }\end{array}$ & A veces (+) \\
$\begin{array}{l}\text { Quistes/nódulos } \\
\text { coloideos }\end{array}$ & $\begin{array}{l}\text { Quísticos, mixtos o sólidos } \\
\text { con spots hiperecogénicos }\end{array}$ & Delimitados + Centrales & $\begin{array}{l}\text { En quistes: }(-) ; \\
\text { nódulos: variable }\end{array}$ & $(-)$ \\
\hline
\end{tabular}

terístico del tejido tímico normal permite reconocerlo con facilidad ${ }^{7} \mathrm{y}$ diferenciarlo de otros nódulos tiroideos ${ }^{8}$ (tabla 1 ).

En un estudio recientemente publicado, Segni y $\operatorname{cols}^{7}$ precisan la apariencia ultrasonográfica del timo intratiroideo en 9 pacientes: corresponde habitualmente a un nódulo solitario, redondeado, ovalado o irregular, hipoecogénico en relación al parénquima tiroideo, con múltiples imágenes hiperecogénicas lineales y/o puntiformes en su espesor que representan septos de tejido conectivo, sin vascularización al Doppler color. El aspecto en US descrito tanto por Segni como por otros autores ${ }^{4,6,9}$ corresponde de forma casi exacta a lo observado en el caso que se presenta. Segni comenta además el resultado del seguimiento a largo plazo de los pacientes (hasta 34 meses) destacando que aquellos de mayor edad (13 y 17 años) mostraron regresión, tanto en tamaño como en la ecogenicidad de las inclusiones tímicas, lo que es concordante con la involución del timo normal observada con la edad, y confirma la naturaleza benigna y autolimitada de esta entidad.

\section{Conclusión}

Las inclusiones tímicas en la glándula tiroidea son infrecuentes, sin embargo, su detección ha ido en aumento en la población pediátrica, posiblemente en relación al uso creciente del ultrasonido.

Esta entidad y sus características ultrasonográficas deben ser conocidas por pediatras y radiólogos para así diferenciarla de otras lesiones tiroideas, evitando exámenes y tratamientos innecesarios a estos pacientes.

\section{Referencias}

1.- Soto G, Horvath E: Ecografía de la tiroides normal y patológica en niños, en Ecografía pediátrica. Buenos Aires: Journal 2011; Cap 3, 29-44.

2.- Niedziela M: Pathogenesis, diagnosis and management of thyroid nodules in children. Endocr Relat Cancer 2006; 13: 427-53.

3.- Pérez Moreno J: Timo intratiroideo ectópico como causa de nódulo tiroideo solitario. An Pediatr (Barc) 2012. http://dx.doi.org/10.1016/j.anpedi.2012.05.023.

4.- Koumanidou C, Vakaki M, Theophanopoulou M, et al: Aberrant thymus in infants: Sonographic evaluation. Pediatr Radiol 1998; 28: 987-9.

5.- Han BK, Yoon H, Suh Y: Thymic ultrasound. II. Diagnosis of aberrant cervical thymus. Pediatr Radiol 2001; 31: 480-7.

6.- Megremis S, Stiakai E, Tritou I, Bonapart I, Tsilimigaki $A$ : Ectopic Intrathyroidal Thymus Misdiagnosed as a Thyroid Nodule: Sonographic Appearance. Journal of Clinical Ultrasound 2008; 36: 443-7.

7.- Segni M, di Nardo R, Pucarelli I, Biffoni M: Ectopic inthratyroidal thymus in children: a long-term follow-up study. Horm Res Paediatr 2011; 75: 258-63.

8.- Lyshchik A, Drozd V, Demidchik Y, Reiners C: Diagnosis of Thyroid Cancer in Children: Value of Gray Scale and Power Doppler US. Radiology 2005; 235: 604-13.

9.- Courcoutsakis N, Patronas N, Filie AC, Carney JA, Moraitis A, Stratakis $C A$ : Ectopic thymus presenting as a thyroid nodule in a patient with the carney complex. Thyroid 2009; 19: 293-6. 